\title{
Bioefficacy of Pectolinaringenin from Clerodendrum phlomidis Linn. F. against Anopheles stephensi and Bhendi Fruit Borer, Earias vittella fab.
}

\author{
Chelliah Muthu ${ }^{1}$, Kathirvelu Baskar ${ }^{1 *}$, Veeramuthu Duraipandiyan ${ }^{3}$, Savarimuthu \\ Ignacimuthu $^{1,2}$ and Naif Abdullah Al-Dhabi ${ }^{3}$ \\ ${ }^{1}$ Entomology Research Institute; Loyola College; Chennai - India. ${ }^{2}$ Deanship of Scientific Research; College \\ Science; King Saud University; Riyadh - Saudi Arabia. ${ }^{3}$ Department of Botany and Microbiology; Addiriyah Chair \\ for Environmental Studies; College of Science; King Saud University; Riyadh - Saudi Arabia
}

\begin{abstract}
Larvicidal activity of pectolinaringenin from Clerodendrum phlomidis was evaluated against Anopheles stephensi and antifeedant, larvicidal and growth inhibitory activities were evaluated against Earias vittella. Pectolinaringenin exhibited larvicidal activity of 100 and $98.24 \%$ against $2^{\text {nd }}$ and $4^{\text {th }}$ instar larvae of Anopheles stephensi at 5ppm concentration. It exhibited $L C_{50}$ values of 0.35 and $0.55 \mathrm{ppm}$ for $2^{\text {nd }}$ and $4^{\text {th }}$ instar larvae, respectively. At 100 ppm concentration, pectolinaringenin exhibited maximum antifeedant activity of $74.00 \%$ and larvicidal activity of 89.98\%. The $L C_{50}$ values were 36.2 and 10.23 ppm for antifeedant and larvicidal, respectively. The compound completely prevented the adult emergence at 50 and 100 ppm concentrations. This is the first report of pectolinaringenin from $\mathrm{C}$. phlomidis evaluated against An. stephensi and $\mathrm{E}$. vittella. The results suggested that the pectolinaringenin from $\mathrm{C}$. philomidis could be used to develop a new botanical formulation to manage vector mosquitoes and agricultural pests.
\end{abstract}

Key words: Anopheles stephensi, adult emergence, Fraction, flavonoid, Effective concentration

\section{INTRODUCTION}

Insect control has been a challenging task for human race since the beginning of agriculture. By the application of chemical pesticides, particularly chlorinated hydrocarbons, pest problem was controlled to a certain level and it was thought that the pest problem was solved. But soon it was realized that the pests developed resistance to these chemicals; besides, they increase the cost of application, leave toxic residues and pollute the environment (Ahmed et al. 1981; Ali and Rizvi 2008). Over-application of these pesticides increase the evolution of insect pests, destroys natural enemies, turns existing harmless species into pests, affects other non-target organisms and contaminates food and feed (WCS 1980). Bami (1997) reported that hardly $0.1 \%$ of the agrochemicals reached the target pests and the remaining $99.9 \%$ entered the environment and affected the non-target organisms. Pentachlorophenol (PCP) containing chemical insecticides inhibit symbiotic nitrogen fixation, which lead to reduce the crop yields and affect seed germination (Fox et al. 2007). Hence, a search for alternate techniques for the

*Author for correspondence: suribaskar@hotmail.com 
management of insect pests is needed.

Several plants have been described as unique species due to their medicinal properties, which have been used for veterinary, human health care and crop protection (Ved and Goraya 2008). Plant-based pesticides are useful for the consumers and agriculturists due to economic considerations and potential health benefits and also for their naturalness (Isman 2008). Plants produce wide range of secondary metabolites such as alkaloids, flavonoids, phenols, etc. These phytochemicals are known to protect the plants from the attack of insect-pests (Ahmad 2007).

There are several reports describing many compounds isolated from different plants with varied biological properties against various pests. Napal et al. (2009) isolated flavonoids from Flourensia oolepis Blake (Asteraceae) and screened for antifeedant activity against Epilachna paenulata (Germar, 1824), Xanthogaleruca luteola (Müller, 1766) and Spodoptera frugiperda (J.E. Smith, 1797). Lakshmi et al. (2010) screened six flavonoids for adulticidal activity against filarial parasite Brugia malayi (S.L. Brug, 1927). Thymol and 1,8-Cineole from essential oils showed antifeedant activity at least concentrations against Chilo partellus (Swinhoe, 1885) (Singh et al. 2011). Antifeedant, larvicidal and growth inhibitory activities of ononitol monohydrate isolated from Senna tora (L.) Roxb. (syn. Cassia tora) against Helicoverpa armigera (Hübner, 1809) and Spodoptera litura (Fabricius, 1775) were reported by Baskar and Ignacimuthu (2012). Baskar et al. (2014) observed that triterpenoid, friedelin isolated from hexane extract of Azima tetracantha (syn. Monetia barlerioides L'Her.) (Salvadoraceae) leaves exhibited biological activity against $H$. armigera and $S$. litura, but did not show any ecotoxicological effect against Cyprinus carpio (Linnaeus, 1758). Allium macrostemon (Amaryllidaceae) Bunge and its major compounds, dimethyl trisulfide and methyl propyl disulfide exhibited strong larvicidal activity against Aedes albopictus (Skuse, 1894) (Liu et al. 2014). Mudalungu et al. (2013) reported that phenanthrene carboxylic acid derivatives, Hexyl-9, 10-dihydroxydec-5-enoate and Methylheneicosane ester derivatives from Fagaropsis angolensis (Engl.) Dale (Rutaceae) showed larvicidal activity against An. gambiae (Giles 1902).

Anopheles stephensi (Liston, 1901) is a causative agent for malaria in urban India. It is predominantly present in China, Afghanistan, Iran, Iraq, India, Bangladesh and Pakistan. Malaria is a major health issue all over the world. Nearly $50 \%$ of the global population (3.4 billion) is facing the risk of malaria. About 207 million malaria cases were recorded in 2012 with estimated malarial deaths of 0.673 million. Africa alone recorded $90 \%$ of malarial deaths in 2012 and most of them were children below five years of age. Efficient preventive and control measures since 2000 have reduced malarial death to $42 \%$ (WHO 2014). Chemical pesticides are mostly unable to kill/control the mosquitoes, which have developed resistance against several chemical pesticides (which also cause severe environmental problems). Due to these reasons, studies are being made to develop natural products to control mosquitoes. Different solvent extracts from Justicia adhatoda L. (syn. Adhatoda vasica) (Acanthaceae), Annona squamosa L, (Annonaceae), Senna auriculata (L.) Roxb. (syn. Cassia auriculata) (Fabaceae), Hydrocotyle javanica Thunb. (Apiaceae), Solanum torvum SW. (Solanaceae), Chrysanthemum indicum L. (Asteraceae), Tridax procumbens L. (Asteraceae) and Vitex negundo L. (Lamiaceae) have shown larvicidal activity against An. stephensi (Kamaraj et al. 2010; 2011). Govindarajan (2011) reported that Eclipta alba L. (Asteraceae), Cardiospermum halicacabum L. (Sapindaceae) and Andrographis paniculata (Burm.f.) Wall. ex Nees (Acanthaceae) exhibited larvicidal activity against An. stephensi. The spotted boll worm, Earias vittella (Fabricius, 1794) is a notorious noctuid pest belonging to the order Lepidoptera and causes serious losses with $50-60 \%$ reduction in cotton yield (Khan and Rao 1960; Sohi 1964). It also causes damage to the seedlings (14.4\%), buds (34-51\%), flowers $(3.2 \%$ flowers) and bolls (3.2-69.0\%) resulting nearly $20 \%$ loss in cotton seed yield (Patel 1949; Kaushik et al. 1969). It damages $79-97 \%$ of the loculi of cotton, Gossypium (Malvaceae) (Sidhu and Sandhu 1977). E. vittella alone is reported to cause $57.1 \%$ fruit infestation and $54.04 \%$ net yield loss in okra (Chaudhary and Dadheech 1989).

Traditionally, Clerodendrum phlomidis Linn F. (Lamiaceae) leaf extract is used to treat skin diseases in livestock (Ramji 1992). C. phlomidis is used as an astringent and also to treat gonorrhea (Rani et al. 1999; Murugesan et al. 2001). C. phlomidis (C. multiflorum) has been used as botanical pesticide to control aphids and red hairy caterpillar, Amsacta albistriga (Walker, 1865) 
(Upadhyay et al. 2002; Singh and Saratchandra 2005). Leaf extracts of this plant were used as grain protectant (Charpot 1998) and to control Heliothis sp. (Ghanch 1998). The present study was aimed at evaluating the mosquito larvicidal, antifeedant, larvicidal and growth inhibitory activities of pectolinaringenin from the chloroform extract of Clerodendrum phlomidis Linn. F. (Lamiaceae) against An. stephensi and Earias vittella.

\section{MATERIAL AND METHODS}

\section{Plant collection, crude extraction, fractionation and isolation of pectolinaringenin}

Extraction, fractionation and isolation of pectolinaringenin from $C$. phlomidis were similar as reported by Muthu et al. (2012).

\section{Rearing of vector mosquitoes}

Larvae of An. stephensi were collected from various stagnant water bodies in Chennai, India. They were cultured in the laboratory for many generations and were maintained at $27 \pm 2{ }^{\circ} \mathrm{C}, 75$ $85 \% \mathrm{RH}$ and photoperiod of $14: 10 \mathrm{~h}$ (light/dark) continuously in the laboratory. Larvae were fed with finely ground dog biscuit (nutritional contents are proteins, fats, sodium, carbohydrates and fatty acids) and yeast extract in the ratio of 3:1. The water was changed daily to avoid scum formation. Pupae were transferred from the trays to a plastic cup containing tap water and placed inside the cage $(30 \times 30 \times 30 \mathrm{~cm}$ dimension) for adult emergence. The emerged adults were reared in the respective cages. The adult colony was provided with $10 \%$ sucrose solution and it was periodically blood-fed on restrained rats. After three days, ovitrap was kept in the cages for egg laying and the eggs were collected and transferred to enamel trays. Newly hatched second and fourth instar larvae were used for the experiment.

\section{Rearing of Earias vittella}

Earias vittella larvae were collected from Thandalam village near Thirupporur, Kancheepuram district, Tamil Nadu. They were reared on glass jars $(21 \mathrm{~cm} \times 15 \mathrm{~cm})$ fed with bhendi fruits up to pupation in the laboratory condition $\left(27 \pm 2^{\circ} \mathrm{C}\right.$ and $75 \pm 5 \%$ relative humidity). After pupation, the pupae (cocoon) were collected and kept in different glass jars covered with white muslin cloth. After the emergence of the adults (8-
10 days), they were fed with $10 \%$ honey solution absorbed in cotton swabs inside the glass jars. Muslin cloth was provided as an oviposition substrate. The eggs laid were kept in a glass jar covered with muslin cloth for hatching. After hatching, the larvae were fed with tender leaves of bhendi (Abelmoschus esculentus) in the neonate stage after that they were fed with bhendi fruit.

\section{Mosquito larvicidal activity}

Bioassay was done using the method of World Health Organization (2014) with second and fourth instar larvae of An. stephensi. Pectolinaringenin was studied at different concentration of $0.5,1.0,2.5$ and $5 \mathrm{ppm}$. A minimum of twenty larvae per replicate and five replicates were maintained (total $\mathrm{N}=100$ ). The experiments with $249 \mathrm{~mL}$ dechlorinated tap water and $1 / 0 \mathrm{ml}$ of the required concentration of test solution was dissolved in water with emulsifier $(0.1 \%$ Tween 80$)$.Tween 80 was used as a negative control. Mortality was observed after $24 \mathrm{~h}$ of treatments.

\section{Antifeedant activity}

Pectolinaringenin was evaluated for their antifeedant activity against $E$. vittella using fruit disc no choice method. Fresh bhendi fruit discs of $10 \mathrm{~mm}$ thickness were used for this study. The bhendi fruit discs were dipped individually in 100 , 50,25 and $12.5 \mathrm{ppm}$ concentrations. The fruit discs dipped in acetone + Tween 80 were used as negative control since it was used to dissolve the compound. In each plastic Petri dish, a wet filter paper was placed to avoid early drying of the test materials and three $3^{\text {rd }}$ instar larvae were introduced into each Petri dish containing five discs of bhendi fruit. Five replicates were maintained for each treatment with 15 larvae per replicate (total $n=75$ ). Progressive consumption of the fruit discs consumed by E. vittella larvae was observed. After $24 \mathrm{~h}$, the fruit discs were weighed using Metler digital balance and the difference between the initial and final weights was calculated. Real consumption was calculated as follows:

Weight loss due to desiccation (D) = initial weight - final weight

Real consumption $=$ initial weight $-($ final weight + D)

The experiment was conducted at laboratory condition $\left(27 \pm 2^{\circ} \mathrm{C}\right)$ with 14 :10h light and dark photoperiod and $75 \pm 5 \%$ relative humidity. 
Antifeedant activity was calculated according to the formula of Bentley et al. (1984):

Antifeedant Consumption in control - Consumption activity $=$ in treated X 100

Consumption in control

\section{Larvicidal activity}

Larvicidal activity was screened using fruit disc no choice method. Bhendi fruit discs were dipped in varied concentrations as mentioned for antifeedant bioassay. After $24 \mathrm{~h}$ of treatment, the larvae were continuously reared on the untreated fresh bhendi fruits. At every $24 \mathrm{~h}$, the diet was changed. Larval mortality was recorded up to $96 \mathrm{~h}$ of treatment. The number of larvae, replicates used and laboratory conditions were the same as in antifeedant experiment. Percent mortality was calculated using Abbott's formula (Abbott 1925).

$$
\begin{array}{cc}
\begin{array}{c}
\text { Abbott corrected } \\
\text { mortality }=
\end{array} & \begin{array}{c}
\% \text { mortality in treatment }- \\
\% \text { mortality in control }
\end{array} \\
\cline { 2 - 2 } & 100-\% \text { mortality in control x100 }
\end{array}
$$

\section{Adult emergence}

The treated larvae were maintained for adult emergence. Adult emergence was calculated by subtracting the number of emerging adults from the total number of pupae.

\section{Statistical analysis}

The data for antifeedant and larvicidal activities and adult emergence were analysed using one-way ANOVA. Significant differences between the treatments were determined using Tukey's multiple range test $(P \leq 0.05)$. The $\mathrm{LC}_{50}$ and $\mathrm{LC}_{90}$ values were calculated using probit analysis (Finney 1971).

\section{RESULTS}

\section{Isolation and Characterization of the compound}

The fraction eluted with the solvent hexane: ethyl acetate (1:1) gave a compound as pale yellow crystal from methanol (melting point $210^{\circ} \mathrm{C}$, Lit. mp $210-212^{\circ} \mathrm{C}$ ). The yield was $850 \mathrm{mg}$. It gave positive ferric reaction by giving green colour with alcoholic ferric chloride for phenol. It also was positive for Shinoda test for flavonoid by giving reddish pink colour with $\mathrm{mg} / \mathrm{HCl}$. TLC over silica gel $\mathrm{G}$ with Chloroform: Ethyl acetate (9:1) as the developing system gave a single spot, pale yellow turning dark yellow, on exposure to ammonia $(\mathrm{Rf}=0.35)$. The purity of the compound was $98.2 \%$ checked using HPLC.

Spectral analyses were done using UV, IR, ${ }^{1} \mathrm{HNMR},{ }^{13} \mathrm{CNMR}$ and EI-MS. The ${ }^{1} \mathrm{HNMR}$ spectrum showed absence of substituent at C-3, H3 appearing as singlet at $\delta=6.56$. The lone aromatic proton $\mathrm{H}-8$ appeared as singlet at $\delta=$ 6.54. The $\mathrm{A}_{2} \mathrm{~B}_{2}$ system in ring $\mathrm{B}$ was shown by two sets of ortho coupled protons at $\delta 7.85$ and $7.03(\mathrm{~J}=9.0 \mathrm{~Hz})$ corresponding to $\mathrm{H}-2^{\prime}, \mathrm{H}-6^{\prime}$ and $\mathrm{H}-3^{\prime}$ and $\mathrm{H}-5^{\prime}$. 4'-OMe appeared as three proton singlet at $\delta-3.94$ and 6-OMe appeared at 3.90. 7$\mathrm{OH}$ appeared as a broad at singlet $\delta 9.39$ and the chelated 5-OH appeared downfield at $\delta 12.96$. The ${ }^{13} \mathrm{CNMR}$ also confirmed the structure of the compound as Pectolinaringenin in the present investigation. The flavonoid carbonyl appeared slightly downfield at $\delta=182.33$. This suggested the un-substituted $\mathrm{C}-3$ with $5-\mathrm{OH}$. The single peak at $\delta 93.09$ was assigned to C-8 and the absence of slightly downfield peak around $\delta 97.0$ found for C-6 in 5,7-oxygenated flavones showed that C-6 was substituted. C-6 OMe appeared at $\delta$ 131.08. $\mathrm{C}-5$ attached to chelated $\mathrm{OH}$ appeared at $\delta 152.72$. The $\delta_{\mathrm{c}}$ values in the ring $\mathrm{B}$ corresponded to pectolinaringenin. The EI-MS gave $\mathrm{M}^{+}$, the molecular ion at $\mathrm{m} / \mathrm{z} 314$ corresponded to the molecular formula $\mathrm{C}_{17} \mathrm{H}_{14} \mathrm{O}_{6}$. The peak at $\mathrm{m} / \mathrm{z} 296$ corresponded to $\left[\mathrm{M}-\mathrm{H}_{2} \mathrm{O}\right]^{+}$. The above data confirmed the structure as Pectolinaringenin (Fig. 1). The molecular formula is $\mathrm{C}_{17} \mathrm{H}_{14} \mathrm{O}_{6}$.

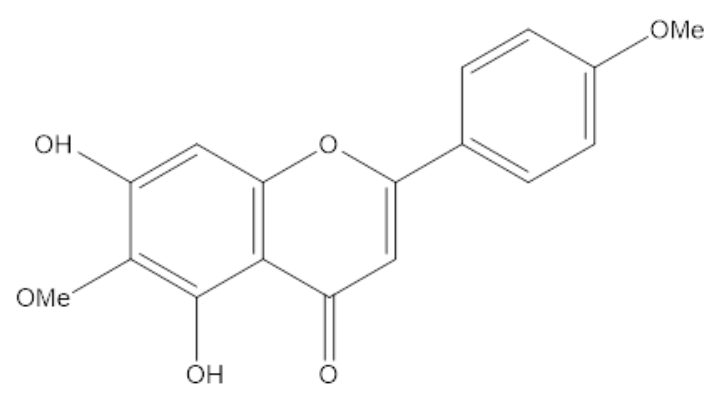

Figue 1 - Pectolinaringenin (5,7-dihydroxy- 4',6dimethoxy-flavone)

\section{Mosquito larvicidal activity}

Pectolinaringenin exhibited larvicidal activity against An. Stephensi at concentration dependent manner. Maximum larvicidal activity of 100 and 98.94\% were noticed at $5 \mathrm{ppm}$ concentration of pectolinaringenin against $2^{\text {nd }}$ and $4^{\text {th }}$ instar larvae, 
respectively. At $2.5 \mathrm{ppm}$ concentration, pectolinaringenin exhibited more than $85 \%$ larvicidal activity. It exhibited the $\mathrm{LC}_{50}$ values of
0.35 and $0.55 \mathrm{ppm}$ against $2^{\text {nd }}$ and $4^{\text {th }}$ instar larvae, respectively. Significant $\chi^{2}$ values indicated the heterogeneity of tested population (Table 1).

Table 1 - Larvicidal activity of pectolinaringenin against human vector mosquito Anopheles stephensi.

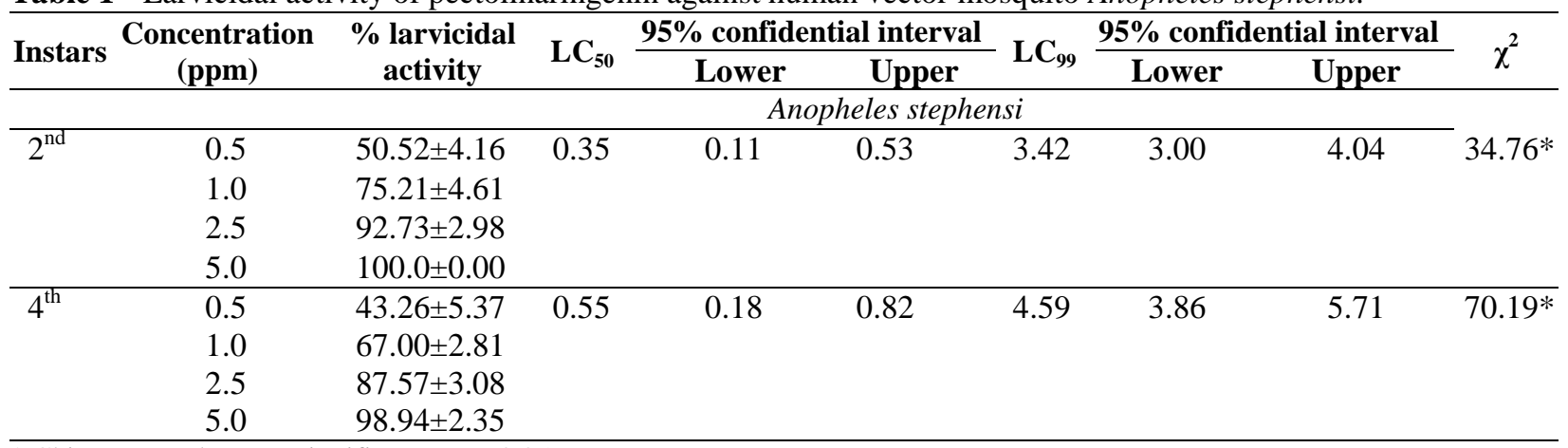

* Chi-square values are significant at $\mathrm{P}<0.05$.

\section{Antifeedant activity}

The pectolinaringenin showed maximum antifeedant activity of $74 \%$ at $100 \mathrm{ppm}$ concentration, followed by $50 \mathrm{ppm}$ concentration against $E$. vittella. The $\mathrm{LC}_{50}$ and $\mathrm{LC}_{90}$ values for the pectolinaringenin were 36.20 and $146.86 \mathrm{ppm}$, respectively (Table 2 ).

\section{Larvicidal activity}

Larvicidal activity of $89.98 \%$ was observed against E. vittella at $100 \mathrm{ppm}$ concentration, followed by 50 and $25 \mathrm{ppm}$ concentrations. The $\mathrm{LC}_{50}$ and $\mathrm{LC}_{90}$ values for the compound were
10.23 and $92.67 \mathrm{ppm}$, respectively. Significant Chi-square values were noticed (Table 2).

\section{Adult emergence}

The pectolinaringenin at 100 and $50 \mathrm{ppm}$ concentrations completely prevented the adult emergence of E. vittella. At 12.5 and $25 \mathrm{ppm}$ concentrations also it inhibited more than $40 \%$ adult emergence of $E$. vittella. When compared to control, all the treatments showed significant reduction of adult emergence of E. vittella (Table 2).

Table 2 - Percent antifeedant, larvicidal activities with effective concentration (ppm) and adult emergence of pectolinaringenin against $E$. vittella.

\begin{tabular}{|c|c|c|c|c|c|c|c|c|c|}
\hline \multirow{2}{*}{ Treatments } & \multirow{2}{*}{$\begin{array}{c}\text { Dose } \\
\text { (ppm) }\end{array}$} & \multirow{2}{*}{ Antifeedant } & \multirow{2}{*}{$\mathbf{L C}_{50}$} & \multicolumn{2}{|c|}{$95 \%$ fiducial limit } & \multirow{2}{*}{$\mathbf{L C}_{90}$} & \multicolumn{2}{|c|}{ 95\% fiducial limit } & \multirow{2}{*}{$\chi^{2}$} \\
\hline & & & & Lower & Upper & & Lower & Upper & \\
\hline & \multicolumn{9}{|c|}{ Antifeedant (\%) } \\
\hline \multirow{4}{*}{ Pectolinaringenin } & 12.5 & $32.53 \pm 3.90^{b}$ & 36.20 & 28.72 & 42.90) & 146.86 & 128.37 & 174.46 & $29.40^{*}$ \\
\hline & 25 & $48.48 \pm 3.50^{\mathrm{c}}$ & & & & & & & \\
\hline & 50 & $62.60 \pm 3.35^{\mathrm{d}}$ & & & & & & & \\
\hline & 100 & $74.00 \pm 1.58^{\mathrm{e}}$ & & & & & & & \\
\hline Control & & $3.10 \pm 1.82^{\mathrm{a}}$ & & & & & & & \\
\hline \multicolumn{10}{|c|}{ Larvicidal (\%) } \\
\hline \multirow{4}{*}{ Pectolinaringenin } & 12.5 & $45.70 \pm 2.99^{\mathrm{d}}$ & 10.23 & 0.43 & 17.57 & 92.67 & 82.07 & 107.92 & $36.7 *$ \\
\hline & 25 & $62.87 \pm 5.43^{\mathrm{e}}$ & & & & & & & \\
\hline & 50 & $77.19 \pm 5.53^{\mathrm{f}}$ & & & & & & & \\
\hline & 100 & $89.98 \pm 3.91^{\mathrm{g}}$ & & & & & & & \\
\hline \multicolumn{10}{|c|}{ Adult emergence (\%) } \\
\hline \multirow{4}{*}{ Pectolinaringenin } & 12.5 & $52.85 \pm 3.91^{\mathrm{b}}$ & & & & & & & \\
\hline & 25 & $50.00 \pm 7.07^{\mathrm{b}}$ & & & & & & & \\
\hline & 50 & $00 \pm 00^{\mathrm{a}}$ & & & & & & & \\
\hline & 100 & $00 \pm 00^{\mathrm{a}}$ & & & & & & & \\
\hline Control & & $92.5 \pm 6.84^{\mathrm{c}}$ & & & & & & & \\
\hline
\end{tabular}

Values represent Mean \pm SD of five replicates ( $\mathrm{n}=75)$; Similar alphabets in a column do not differ significantly using Tukey's test $(\mathrm{P} \leq 0.05) ;{ }^{*}$ Chi-square values are significant at $\mathrm{P}<0.05$. 


\section{DISCUSSION}

In the present study, plant derived pectolinaringenin exhibited $100 \%$ larvicidal activity against An. stephensi. These findings agreed with those of Senthil Nathan et al. (2005) who reported that natural compounds of azadirachtin, salannin, deacetylgedunin, Gedunin, 17-Hydroxyazadiradione and deacetylnimbin exhibited larvicidal activity against An. stephensi. Leaves and seed methanol extract of Melia azedarach (Meliaceae) exhibited more than $70 \%$ larvicidal activity against $2^{\text {nd }}$ and $4^{\text {th }}$ instar larvae of An. stephensi (Senthil Nathan et al. 2006). Piperitenone oxide isolated from the essential oil of Mentha spicata L. var. viridis (L.) (Lamiaceae) exhibited larvicidal activity against An. stephensi (Tripathi et al. 2004). Mullai et al. (2008) reported that different organic solvent extracts of Citrullus vulgaris Schrad. by L. H. Bailey (Cucurbitaceae) exhibited larvicidal activity against An. stephensi. Pectolinaringenin exhibited $100 \%$ larvicidal activity against An. stephensi in the present study. The present study was in agreement with the findings of Medhi et al. (2010) who reported that major constituents of 1,8 -cineole $(69.46 \%), \gamma-$ Terpinene $(15.10 \%), \alpha$-Pinene $(5.47 \%)$ and Globulol (2\%) from Eucalyptus camaldulensis Dehnh (Myrtaceae) exhibited larvicidal activity against An. stephensi. Flindersine from Toddalia asiatica Lam. (Rutaceae) exhibited larvicidal activity against $A n$. Stephensi by Duraipandiyan et al. (2014)

The secondary metabolites produced by the plants act as defensives against insects. Different plant extracts with various organic solvents extracted in varied proportions yield secondary plant metabolites, which possess various types of biological activities to protect the plants from insects (Sharma and Bhist 2008). Fraenkal (1959) stated that food preference by the insects is based solely on the presence or absence of secondary plant metabolites. In this study, pectolinaringenin showed promising antifeedant activity against $E$. vittella. The results were in agreement with the findings of Napal et al. (2009) who reported that antifeedant activity of flavonone, pinocembrin isolated from ethanolic extract of Flourensia oolepis Blake (Asteraceae) aerial parts exhibited more than $80 \%$ antifeedant activity against $E$. paenulata, X. luteola and S. frugiperda.

The present results revealed that pectolinaringenin showed promising antifeedant activity. Bioassay- guided fractionation of the extracts of Nothofagus dombeyi Mirb. (Oerst.) (Nothofagaceae) and $N$. Pumilio (Poepp. and Endl.) Krasser yielded several triterpenes and flavonoids including 2-Oacetylmaslinic acid, 3-O-acetyl 20,24,25trihydroxydammarane, and 3,20,24,25tetrahydroxydammarane. They were screened for antifeedant activity against larvae of Ctenopsteustis obliquana (Walker, 1863) and it was noticed that 12-hydroxyoleanolic lactone and pectolinarigenin from $N$. dombeyi and dihydrooroxylin A from $N$. pumilio exhibited significant antifeedant activity (Thoison et al. 2004).

In the present investigation, a flavonoid, pectolinaringenin exhibited good antifeedant activity at 100 and $50 \mathrm{ppm}$ concentration. This finding coincided with the results of Simmonds and Stevenson (2001) who studied four isolated flavonoids from various wild varieties of Cicer (Fabaceae), namely judaicin 7-O-glucoside, 2methoxy-judaicin, judaicin and maackiain against the feeding behaviour and development of $H$. armigera. All the four isoflavonoids showed antifeedant activity against $H$. armigera at 100 ppm concentration. Antifeedant activity of six neoclerodane diterpenoides isolated from Clerodendrum species were evaluated against $E$. vittella and S. litura by Kumari et al. (2003) and it was observed that all the compounds exhibited more than $65 \%$ antifeedant activity against both the pests at $10 \mu \mathrm{g} / \mathrm{cm}^{2}$ concentrations.

Simmonds et al. (1990) reported that the antifeedant activity of flavonoids such as chalcones, flavones and flavanones was due to the predominant stimulation of the deterrent neurons in the medial sensillum stylonicum and more than one receptor could be involved. Some flavonoids and flavonoid-containing extracts possess anthelmintic and nematicidal activity, which induce embryonic and larval lethality in Bursaphelenchus xylophilus (Steiner \& Buhrer, Nickle) and Caenorhabditis elegans (Maupas, 1900) (Lee et al. 2008; Kim et al. 2009).

The isolated compound, pectolinaringenin exhibited maximum larval mortality at $100 \mathrm{ppm}$. At lower concentration (12.5 ppm), it exhibited more than $50 \%$ larval mortality. This finding was in accordance of Kumari et al. (2003) who reported that six neo-clerodane diterpenoides isolated from Clerodendrum species at $10 \mu \mathrm{g} / \mathrm{cm}^{2}$ exhibited 20 and 44\% larval mortality against $E$. vittella and $S$. litura, respectively. Strongest 
insecticidal activity of isoflavones were from the stems without bark of Endosamara racemosa (Roxb.) R. Geesink (syn: Millettia racemosa) (Leguminosae) (Kumar 1988).

In the present investigation, pectolinaringenin either completely reduced the adult emergence or larval-pupal intermediate or pupicidal activities were observed. This was in agreement with Rembold and Garcia (1989), who observed that the treated Rhodnius prolixus (Stål, 1859) larvae managed to enter the pupal stage even at low concentration of azadirachtin but emerged adults were not able to reproduce, which implied that azadirachtin inhibited ecdysis. Adults developed from the treated larvae were mostly deformed (Sharma and Jalan 1997).

In the present finding, the compound, pectolinaringenin prevented $100 \%$ adult emergence at 100 and $50 \mathrm{ppm}$ concentrations. Our findings corroborate with the earlier findings of Abdelgaleil and El-Aswad (2005) who evaluated Methyl 6-hydroxyangolensate and 3,7dideacetylkhivorin derived from Khaya ivorensis A. Chev. (Meliaceae) against $S$. littoralis (Boisduval, 1833) and observed reduction in larval growth, pupation, adult emergence and egg hatchability. Six neo-clerodane diterpenoides were isolated from Clerodendrum species by Kumari et al. (2003) and observed that all the compounds prolonged the larval and pupal durations of $E$. vittella compared to control. Clerodendrin B was the most promising compound which prolonged the larval and pupal durations and reduced the adult emergence.

Antifeedant activity of pectilonaringenin was maximum against $E$. vittella in a dose-dependent manner. The activity could be due to the functional groups such as hydroxyl, methoxyl and carbonyl present in the compound. The compound had hydroxyl groups at $5^{\text {th }}$ and $7^{\text {th }}$ position in A- ring, which contributed to strong antifeedant activity. The pyran ring had C-4 carbonyl, which was essential for high antifeedant activity. The methoxyl group at C-4' in the B-ring contributed to mild activity. Phagodeterrent activity of the pectilonaringenin coincided with the results of Ohmura et al. (2000) who reported that the presence of hydroxyl group at $7^{\text {th }}$ position in the A-ring and carbonyl group at C-4 in the pyran ring in naringenin contributed to higher antifeedant activity of subterranean termite, Coptotermes formosanus (Shiraki, 1909) than the C-4' in the Bring. Medeiros et al. (1994) reported that keto group at C-4 in quercetin, karanjin, chrysoeriol and butein showed strong antifeedant activity and the presence of 7-hydroxyl group in the flavone was responsible for the highest antifeedant activity against Mythmina unipuncta (Haworth, 1809). Pectolinaringenin isolated from Clerodendron siphonenthus was screened against Sitophilus oryzae (Linnaeus, 1763) by Pal et al. (1989) and reported that the compound inhibited the feeding. Kaemperol and quercetin flavonoids having an oxidised C-ring, inhibited feeding in Scolytus multistriatus (Marsham, 1802) (Norris 1970).

\section{CONCLUSION}

The results showed that pectolinaringenin from $C$. phlomidis chloroform extract exhibited promising mosquito larvicidal, antifeedant and larvicidal activities and reduced the adult emergence of $E$. vittella. Pectolinaringenin could be effectively used to develop a novel pesticidal formulation for disease causing vector mosquitoes and agricultural pest management programme.

\section{ACKNOWLEDGEMENTS}

This project was supported by King Saud University, Deanship of Scientific Research, Addiriyah Chair for Environmental Studies.

\section{REFERENCES}

Abbott WS. A method of computing the effectiveness of an insecticide. J Econ Entomol. 1925; 18: 265-267.

Ahmad M. Insecticide resistance mechanisms and their management in Helicoverpa armigera (Hubner)-A review. J Agric Res. 2007; 45: 319-335.

Ahmed SM, Chander H, Pereira J. Insecticidal potential and biological activity of India indigenous plants against Musca domestica. Intl Pest Control. 1981; 23: 170-175

Ali A, Rizvi PQ. Influence of aphid species on the development and predation of Menochilus sexmaculatus Fabricius (Coleoptera: Coccinellidae). J Eco-friendly Agric. 2008; 3: 34-137.

Bami L. Pesticide use in India-Tenquestions. Chem Weekl. 1997; 4: 7-10. 
Baskar K, Duraipandiyan V, Ignacimuthu S. Bioefficacy of the triterpenoid friedelin against Helicoverpa armigera (Hub.) and Spodoptera litura (Fab.) (Lepidoptera: Noctuidae). Pest Manag. Sci. 2014; 70, 1877-1883.

Baskar K, Ignacimuthu S. Antifeedant, larvicidal and growth inhibitory effects of ononitol monohydrate isolated from Cassia tora L. against Helicoverpa armigera (Hub.) and Spodoptera litura (Fab.) (Lepidoptera: Noctuidae). Chemosphere. 2012; 88: 384-388.

Bentley MD, Leonard DE, Stoddard WF, Zalkow LH. Pyrrolizidine alkaloids as larval feeding deterrents for spruce budworm, Choristoneura fumiferana (Lepidoptera: Tortricidae). Ann Entomol Soc Am. 1984; 77: 393-397.

Charpot RT. Leaves of Clerodendron phlomidis for preserving grains. Honey Bee. 1998; 9, 16.

Chaudhary HR, Dadheech LN. Incidence of insect attacking okra and the avoidable losses caused by them. Ann Arid Zone. 1989; 28: 305-307.

Duraipandiyan V, Baskar K, Muthu C, Ignacimuthu S, Al-Dhabi NA. Bioefficacy of Flindersine against Helicoverpa armigera Hübner, Spodoptera litura Fabricius, Anopheles stephensis Liston. and Culex quinquefasciatus Say. Braz. Arch. Biol. Technol. (Accepted).

Finney DJ. Probit Analysis, 3rd edition. Cambridge University Press, London, UK. 1971; pp. 383.

Fox JE, Gulledge J, Engelhaupt E, Burow ME, McLachlan JA. Pesticides reduce symbiotic efficiency of nitrogen-fixing rhizobia and host plants. Proc Nat Acad Sci. 2007; 104: 10282-287.

Fraenkal GS. The Raison detre of secondary plant substances. Science. 1959; 129: 1466-1470.

Govindarajan M. Evaluation of indigenous plant extracts against the malarial vector, Anopheles stephensi (Liston) (Diptera: Culicidae). Parasitol Res. 2011; 109: 93-103.

Isman MB. Perspective botanical insecticides, for richer, for poorer. Pest Manag Sci. 2008; 64: 8-11.

Kamaraj C, Bagavan A, Elango G, Zahir AA, Rajakumar G, Marimuthu S, Santhoshkumar T, Rahman AA. Larvicidal activity of medicinal plant extracts against Anopheles subpictus \& Culex tritaeniorhynchus. Ind J Med Res. 2011; 134: 101106.

Kamaraj C, Rahman AA, Bagavan A, Zahir AA, Elango G, Kandan P, Rajakumar G, Marimuthu S, Santhoshkumar T. Larvicidal efficacy of medicinal plant extracts against Anopheles stephensi and Culex quinquefasciatus (Diptera: Culicidae). Trop Biomed. 2010; 27: 211-219.

Kaushik VK, Rathore VS, Sood NK. Incidence of bollworms and losses caused to cotton in Madhya Pradesh. Ind J Entomol. 1969; 31: 175-177.
Khan Q, Rao VP. Pests of cotton. In, Cotton in India-A Monograph. In: Dastur RH, Asana RD, Sawhney K, Sikka SM, Vasudeva RS, Khan Q, Rao VP, Sethi BL. (Eds.), Indian Central Cotton Committee, Bombay, India, 1960; 217-301.

Kim KS, Kawasaki I, Chong Y, Shim YH. Inhibition of overexpressed CDC-25.1 phosphatase activity by flavone in Caenorhabditis elegans. Mol Cells. 2009; 27: 345-350.

Kumar RJ, Krupandanam GLD, Srimanarayana G. Isoflavans from Millettia racemosa. Phytochem. 1988; 25: 67-72.

Kumari GNK, Balachandran J, Aravind S, Ganesh MR, Govindachari TR. Antifeedant and growth inhibitory effects of some neo-clerodane diterpenoids isolated from Clerodendron species (Verbenaceae) on Earias vittella and Spodoptera litura. J Agric Food Chem. 2003; 51: 1555-1559.

Lakshmi V, Joseph SK, Srivastava S, Verma SK, Sahoo MK, Dube V, Mishra SK, Murthy PK. Antifilarial activity in vitro and in vivo of some flavonoids tested against Brugia malayi. Acta Tropica. 2010; 116: 127133.

Lee SE, Kim MR, Kim JH, Takeoka GR, Kim TW, Park BS. Antimalarial activity of anthothecol derived from Khaya anthotheca (Meliaceae). Phytomedicine. 2008; 15: 533-535.

Liu XC, Liu Q, Zhou L, Liu ZL. Evaluation of larvicidal activity of the essential oil of Allium macrostemon Bunge and its selected major constituent compounds against Aedes albopictus (Diptera: Culicidae). Parasit Vectors. 2014; 7: 184.

Lwande W, Hassanali A, Njorge PW, Bentley MD, Monache FD, Jondiko JI. A new 6ahydroxypterocarpan with insect antifeedant and antifungal properties from the roots of Tephrosia hildebrandtii Vatke. Insect Sci Appl. 1985; 6: 537541.

Medeiros J, Lima E, Medeiros E. Relationships between the structure of flavonoids and antifeedant activity against Mythimna unipuncta (Haworth) (Lepidoptera: Noctuidae). Arquipe'lago. Life and Marine Sciences. 1994; 12A: 63-66.

Medhi SM, Reza SA, Mahnaz K, Reza AM, Abbas H, Fatemeh M, et al. Phytochemistry and larvicidal activity of Eucalyptus camaldulensis against malaria vector, Anopheles stephensi. Asian Pac J Trop Med. 2010; 3: 841-845.

Mudalungu CM, Matasyoh JC, Vulule JM, Chepkorir R. Larvicidal compounds from Fagaropsis angolensis leaves against malaria vector (Anopheles gambiae). Int J Malaria Res Rev. 2013; 1: 1-7.

Mullai K, Jebanesan A, Pushpanathan T. Mosquitocidal and repellent activity of the leaf extract of Citrullus vulgaris (cucurbitaceae) against the malarial vector, Anopheles stephensi liston (diptera culicidae). Eur Rev Med Pharmacol Sci. 2008; 12: 1-7. 
Murugesan T, Saravanan KS, Lakshmi S, Ramya G, Thenmozhi K. Evaluation of psychopharmacological effects of Clerodendrum phlomidis Linn. extract. Phytomedicine. 2001; 8: 472-476.

Muthu C, Reegan AD, Kinsley S, Ignacimuthu S. Larvicidal activityof pectolinaringenin from Clerodendrum phlomidis L. against Culex quinqufasciatus Say and Aedes aegypti L. (DipteraL Culicidae). Parasitol Res. 2012; 111: 1059-65.

Napal GND, Carpinella MC, Palacios SM. Antifeedant activity of ethanolic extract from Flourensia oolepis and isolation of pinocembrin as its active principle compound. Bioresource Technol. 2009; 100: 36693673.

Norris DM. Quinol stimulation and quinol deterrency of gestation by Scolytus multistriatus (Coleoptera: Scolytidae). Ann Entomol Soc Am. 1970; 63: 476478.

Numata A, Takemura T, Ohbayashi H, Katsuno T, Yamamoto K, Sato K, Kobayashi S. Antifeedant for the larvae of the yellow butterfly, Eurema hecabe Mandarina in Lycoris radiata. Chem Pharm Bull. 1983; 31: 2146-2149.

Ohmura W, Doi S, Aoyama M, Ohara S. Antifeedant activity of flavonoids and related compounds against the subterranean termite Coptotermes formosanus Shiraki. J Wood Sci. 2000; 46: 149-153.

Pal S, Chowdhury A, Adityachaudhury N. Isolation of rice weevil feeding inhibitors uncinatone and pectolinarigenin from Clerodendron siphonenthus. $J$ Agric Food Chem. 1989; 37: 234-236.

Patel RM. Control of spotted bollworm (Earias fabia S.) in Baroda. Ind Cotton Grow Rev. 1949; 3: 135144.

Ramji MP. Treatment for skin disease, leaf extract of 'Arani'(Clerodendrum phlomidis). Honey Bee. 1992; 3: 21.

Rani S, Ahamed N, Rajaram S, Saluja R, Thenmozhi S, Murugesan T. Anti-diarrhoeal evaluation of Clerodendrum phlomidis Linn, leaf extract in rats. $J$ Ethnopharmacol. 1999; 68: 315-319.

Rembold H, Garcia EC. Azadirachtin inhibits Trypanosoma cruzi infection of its triatomine insect host, Rhodnius prolixus. Naturwissenschaften. 1989; 76: 77-78.

Senthil Nathan S, Savitha G, George DK, Narmadha A, Suganya L, Chung PG. Efficacy of Melia azedarach L. extract on the malarial vector Anopheles stephensi Liston (Diptera: Culicidae). Bioresource Technol. 2006; 97, 1316-1323.

Senthil Nathan, S, Kalaivani K, Murugan K. Effects of neem limonoids on the malaria vector Anopheles stephensi Liston (Diptera: Culicidae). Acta Tropica. 2005; 96: 47-55.
Sharma PD, Jalan MS. Relative efficacy and persistence of different insecticides for the control of Helicoverpa armigera on cotton. Pestol. 1997; 21: 12-15.

Sharma RK, Bisht RS. Antifeedant activity of indigenous plant extracts against Spodoptera litura Fabricius. J Insect Sci. 2008; 21: 56-60.

Sidhu AS, Sandhu SS. Damage due to spotted bollworm (Earias vittella. Fab.) in relation to the age of the bolls of Hirsutum variety J-34. J Res Punjab Agr Univ. 1977; 14: 184-187.

Simmonds MSJ, Blaney WM, Delle F, Bettolo G, Marini B. Insect antifeedant activity associated with compounds isolated from species of Lonchocarpus and Tephrosia. J Chem Ecol. 1990; 16: 365-380.

Simmonds MSJ, Stevenson PC. Effects of isoflavonoids from Cicer on larvae of Helicoverpa armigera. J Chem Ecol. 2001; 27: 965-977.

Singh R, Koul O, Rup PJ, Jindal J. Oviposition and feeding behaviour of the maize borer, Chilo partellus, in response to eight essential oil allelochemicals. Entomol Exp Appl. 2011; 138: 55-64.

Singh RN, Saratchandra B. The development of botanical products with special reference to seriecosystem. Caspian J Environ Sci. 2005; 3: 1-8.

Sohi GS. Pests of cotton. In, Entomology in India In: Pant NC. (Ed.), Entomological Society of India, New Delhi, India, 1964; 129-132.

Sutherland ORW, Russell GB, Biggs DR, Lane GA. Insect feeding deterrent activity of phytoalexin isoflavonoids. Biochem System Ecol. 1980; 8: 73-75.

Thoison O, Sevenet T, Niemeyer HM, Russell GB. Insect antifeedant compounds from Nothofagus dombeyi and N. pumilio. Phytochem. 2004; 65: 21732176.

Tripathi AK, Prajapati V, Ahmad A, Aggarwal KK, Khanuja SPS. Piperitenone oxide as toxic, repellent, and reproduction retardant toward malarial vector Anopheles stephensi (Diptera: Anophelinae). J Med Entomol. 2004; 41: 691-698.

Upadhyay KK, Mukerji KG, Chamola BP. Biocontrol potential and its exploitation in sustainable agriculture. Springer, New York, 2002; 97.

Ved DK, Goraya GS. Demand and supply of medicinal plants in India, Bishen Singh, Mahendra Pal Singh, Dehra Dun, India, 2008.

World Conservation Strategy (WCS) 1980. International Union for the Conservation of Nature and Natural Resources, Gland, Switzerland.

World Health Organization, 2014. http://www.who.int/ features/factfiles/malaria/en/ 10/June/2014.

Received: December 06, 2014; Accepted: February 23, 2015. 